\title{
Anestezi Uygulayıcılarında Tükenmişlik Sendromu Sıklığının Araştırılması
}

\section{Investigation of The Frequency of Burnout Syndrome in Anesthesiologists}

\author{
Mustafa BIÇAK ${ }^{1}(\mathbb{D})$, Feyzi ÇELIK ${ }^{2}$
}

\author{
${ }^{1}$ Sağlık Bilimleri Üniversitesi Gazi Yaşargil Eğitim ve Araştırma Hastanesi Anestezi ve Reaminasyon Kliniği, Diyarbakır, TÜRKiYE \\ 2 Dicle Üniversitesi Tıp Fakültesi Anesteziyoloji ve Reanimasyon Anabilim Dalı, Diyarbakır, TÜRKiYE
}

Öz.

Amaç: Bu çalışmada Diyarbakır ilinde anestezi uygulayııılarındaki tükenmişlik sendromu sıklık düzeylerinin değerlendirilmesini amaçladık.

Materyal ve Metod: Çalışmaya Gazi Yaşargil Eğitim ve Araştırma Hastanesi ve Dicle Üniversitesi Tıp Fakültesinde görevli 20 asistan doktor, 25 anestezi uzmanı ve 50 anestezi teknikeri dâhil edildi. Katılımcılar tarafından Maslach Tükenmişlik Ölçeği, Minesota iş Doyum Ölçeği ve Sosyo-demografik Veri Formu dolduruldu.

Bulgular: Minesota Doyum ve Maslach Tükenmişlik Ölçeği güvenirlik analizine göre cronbach alfa güvenirlik katsayısı içsel doyumda 0,87; dışsal doyumda 0,85; genel doyumda 0,92 bulundu. Tükenmişlik ölçeği duygusal tükenmede 0,83 ; duyarsızlaşmada 0,78 ve kişisel başarıda 0,73 bulundu. Doktorların puan ortalaması içsel doyumda 3,10 ; dışsal doyumda 2,57; genel doyumda 2,89 hesaplandı. Maslach tükenmişlik ölçeği alt boyut puanı duygusal tükenmede 2,24, duyarsızlaşmada 1,20 ve kişisel başarıda 2,58 bulundu. Minesota doyum ölçeği alt boyutları puanlarından içsel doyum, dışsal doyum ve genel doyum puanı hastane çalışanlarında branşlara göre farklılık gösterdi. En yüksek doyum puanının uzman doktorlarda, en düşük doyum puanınınsa teknikerlerde olduğu saptandı. Maslach tükenmişlik ölçeği alt boyut puanları branşlara göre farklılık göstermedi. Uzman doktor ve teknikerde doyum ve tükenmişlik ölçeği alt boyut puanları cinsiyete göre anlamlı farklılık göstermedi. Asistan doktorlarda duygusal tükenme ve duyarsızlaşma puanları cinsiyete göre farklılık gösterdi. Erkek asistan doktorların duygusal tükenme ve duyarsızlaşma puanları daha yüksekti. Uzman ve asistan doktorlarda doyum ve tükenmişlik ölçeği puanları medeni duruma göre farklılık göstermedi. Teknikerlerde ise duyarsızlaşma puanının bekârlarda daha yüksek olduğu saptandı.

Sonuç: Anket çalışmasının bulguları, bireye yönelik müdahalelerin daha etkili olduğunu göstermektedir. Tükenmişliğin tüm alt boyutlarında etkili olan çalışmaların daha fazla olması istenen bir durum olmakla birlikte bunun az sayıdaki çalışmada sağlanabildiği görülmektedir.

Anahtar Kelimeler: Diyarbakır, Anestezi, Tükenmişlik Sendromu, Sıklık

\section{Abstract}

Background: In this study, we aimed to assess the frequency of burnout syndrome in anesthesia practitioners in the province of Diyarbakır.

Materials and Methods: The study was conducted with 20 assistant physicians, 25 specialists and 50 anesthesia technicians, who agreed to participate in the research, working in Gazi Yaşargil Training and Research Hospital and Dicle University Faculty of Medicine, Department of Anesthesiology and Reanimation. Maslach Burnout Scale, Minnesota Job Satisfaction Scale and Socio-demographic Data form were filled by the participants.

Results: According to the results of reliability analysis of the Minnesota Satisfaction Scale and Maslach Burnout Inventory sub-scales, Cronbach's Alpha values were 0.87 for the intrinsic satisfaction, 0.85 for extrinsic satisfaction, 0.92 for overall satisfaction. The burnout inventory sub-scales were found 0.83 for emotional exhaustion, 0.78 for depersonalization and 0.73 for personal accomplishment. The doctors' average intrinsic satisfaction score was calculated to be 3.10 , the average extrinsic satisfaction score was 2.57 , and overall satisfaction score was 2.89 . Maslach Burnout Inventory's emotional exhaustion sub-scale score was 2.24, depersonalization sub-scale score was 1.20 , and personal accomplishment sub-scale score was calculated to be 2.58. Intrinsic satisfaction, extrinsic satisfaction, and general satisfaction scores of the Minnesota satisfaction sub-scale scores differed among the hospital staff according to the branches. It was observed that specialists had higher satisfaction scores than other branches and technicians had the lowest satisfaction scores. Maslach Burnout Inventory sub-scale scores did not show differences in terms of the branches. There was no significant difference between the gender in the satisfaction and burnout sub-scale scores of specialist physicians and technicians. Emotional exhaustion and depersonalization scores of assistant physicians showed difference according to gender. Male assistant physicians were found to have higher emotional exhaustion and depersonalization scores. Satisfaction and burnout sub-scale scores of specialists and assistant physicians were no significant difference in terms of their marital status. Depersonalization scores of single technicians were found to be higher.

Conclusion: The findings of the survey study show that individual-oriented interventions are more effective. Although it is desirable to have more studies effective on all sub-scales of the burnout, it is seen that it can be achieved with a small number of studies as well.

Key Words: Diyarbakır, Anesthesia, Burnout syndrome, Frequency
Sorumlu Yazar/Corresponding Author

Dr. Mustafa BıÇAK

Sağlık Bilimleri Üniversitesi Gazi

Yaşargil Eğitim ve Araştırma Hastanesi Anestezi ve Reaminasyon Kliniği,

21010

Diyarbakır, TÜRKIYE

E-mail: drmustafabicak@gmail.com

Geliş tarihi / Received: 16.04.2021

Kabul tarihi / Accepted: 31.05.2021

DOI: 10.35440/hutfd.917235

Bu çalıșma, 4-5 Mayıs 2018'de

Multicongress Adana'da sözlü sunu

olarak sunulmuştur. 


\section{Giriş}

"Tükenmişlik" kavramını tarihte ilk defa Freudenburg tanımlamış olsa da şimdiki kabul gören tanımlama 1981'de Maslach tarafından yapılmıştır $(1,2)$. Maslach tükenmişlik tanımı, kişinin profesyonel iş yaşamında ve diğer insanlarla olan ilişkilerinde olumsuzluklara yol açan özsaygı yitimi, kronik yorgunluk, çaresizlik ve umutsuzluk duygularının gelişimiyle birlikte seyreden fiziksel, duygusal ve entelektüel tükenmeyle karakterize bir sendromdur ve üç ayrı alt kategoriye ayrılmıştır; i) Duygusal tükenme, ii) Depersonalizasyon ve iii) Kişisel başarı eksikliği (3).

Literatürdeki çalışmalarda sağlık çalışanlarında tükenmişlik sendromu sıklığı diğer meslek gruplarına oranla daha yüksek bulunmuştur (4-6). Tükenmişliğin en önemli sonucu sunulan hizmette bozulmalara neden olması, ayrıca bireylerde ciddi fiziksel ve zihinsel sorunlar oluşturmasıdır. Bu nedenle kaliteli sağlık hizmeti yürütülmesi ve sağlık çalışanlarının ciddi sağlık sorunları yaşamaması için tükenmişlik sendromu ve predispozan faktörler ayrıntılı bir şekilde değerlendirilmelidir.

Psikosomatik hastalıkların ortaya çıkışı veya var olan rahatsızlığın artışıyla depresif yakınmalarda artış, işten ayrılma, iş doyumunun azalması, uykusuzluk, konsantre olamama, gastrointestinal problemler, sosyal izolasyon, yorgunluk, libido azalması ve madde kullanımında artış görülebilmektedir $(7,8)$.

Anestezi uygulayıcılarının çalışma alanları sıklıkla kapalı, karanlık ve havalandırmanın yetersiz olduğu ortamlardır. Anestezi uygulayıcıları böylesi bir ortamda uzun ve yorucu bir çalışmanın yanı sıra; Anestezik gazlar, radyasyon, uygun olmayan ergonomik koşullar, yetersiz havalandırma, gürültü, bulaşıcı hastalıklar, hasta ve hasta yakınlarının uyguladığı şiddet riskleriyle karşı karşıyadırlar. Bu nedenle tükenmişlik sendromu anestezi uygulayıcıları açısından kesinlikle değerlendirilmesi gereken bir durumdur.

Çalışmamızda Diyarbakır ilinde anestezi uygulayıcılarındaki tükenmişlik sendromu sıklığını değerlendirmeyi amaçladık.

\section{Materyal ve Metod}

Çalışmaya Diyarbakır ilinde çalışan ve gönüllü olarak katılmayı kabul eden Gazi Yaşargil Eğitim ve Araştırma Hastanesi ile Dicle üniversitesi Tıp Fakültesi Anesteziyoloji ve Reanimasyon bölümünde görevli asistan doktor, uzman doktor ve anestezi teknikerleri dâhil edildi. Çalışma için 07.10.2016 tarih ve 319 sayılı etik kurul kararı ile Dicle Üniversitesi Tıp Fakültesi Etik Kurulu'ndan onay alındı. Çalışmaya toplam 50 tekniker, 20 asistan doktor ve 25 uzman doktor dâhil edildi.

Katılımcılara kapalı zarflar içinde Maslach Tükenmişlik Ölçeği, Minesota İş Doyum Ölçeği ve Sosyo-demografik Veri Formu sunuldu. Katılımcılara formların içeriği hakkında ayrıntılı bilgi verildi ve puanlama şekli anlatılıp doldurmaları istendi. Araştırmaya katılan uzman doktor, asistan ve sağlık personelinin tükenmişlik düzeylerinin belirlenmesinde Maslach Tükenmişlik Ölçeği'nin (Maslach Burnout Inventory- MBI) Ergin (3) tarafından Türkçeye uyarlanmış formu kullanıldı. Ölçeğin özgün formunun değerlendirilmesinde yer alan "hiçbir zaman, yılda birkaç kere, ayda bir, ayda birkaç kere, haftada bir, haftada birkaç kere, hergün" şeklindeki 7 basamaklı cevap seçeneklerinin uygun olmadığı değerlendirildiğinden "hiçbir zaman, çok nadir, bazen, çoğu zaman, her zaman" ifadelerine karşılık gelen ve 0-4 arasında puanlandırılan 5'li Likert tipi cevap seçeneği kullanılmaktadır. Ölçeğin Türkçeye uyarlanması çalışmalarında yapılan analizler sonucu ölçeğin orijinalinde olduğu gibi üç faktöre yayıldığı görülmüştür. Bu nedenle ölçek genel tükenmişlik seviyesini ölçmek için kullanılabildiği gibi, üç alt faktör olan duygusal tükenme, duyarsızlaşma ve kişisel başarı hissi azalması seviyelerini ayrı ayrı ölçmek için de kullanılabilmektedir (3).

Araştırmanın verileri; Maslach tükenmişlik ölçeğini de içeren soru formları ile sosyo-demografik özellikler, kişiselalışkanlıklar, aile ve haneye ilişkin özellikler sorgulanarak elde edildi.

Katılımcıların tükenmişlik durumu ile ilgili olarak da Maslach Tükenmişlik Ölçeği ve Minnesota İş Doyumu Ölçeği kullanıldı. Ölçek genel tükenmişlik seviyesini belirlemenin yanısıra, duygusal tükenme, duyarsızlaşma ve kişisel başarı hissini ölçme amaçlı da kullanılabilmektedir (3).

\section{istatiksel Analiz}

İstatistiksel analizler için SPSS Version 24 kullanıldı. Sayısal veriler ortalama \pm standard sapma, kategorik veriler frekans ve \% olarak verildi. Sayısal verilerin normal dağılıp dağılmadığı Kolmogorov-Smirnov testi ile değerlendirildi. Normal dağılan parametrik verilerde Student $t$ testi ve One-way ANOVA testi; normal dağılmayan ve kategorik verilerde ise Mann-Whitney $U$ testi ve Kruskall-Wallis testi uygulandı. Gruplarda kategorik verilerin karşılaştırılması ki-kare testi ile yapıldı ve sonuçlar \%n olarak verildi. İkili grup karşılaştırmaları ki-kare testi sonucuna göre post-Hoc Bonferoni testi ile yapıldı. Korelasyon değerlendirmeleri; normal dağılan numeric veriler pearson korelasyon testi ile normal dağılıma uymayan numerik veriler spearman korelasyon testi ile yapıldı. İstatistiksel anlamlılık düzeyi $p<$ 0.05 olarak kabul edildi.

\section{Bulgular}

Uzman doktorların \%57,9'unun, teknikerlerin \%25,9'unun ve asistan doktorların \%37'sinin kadın olduğu saptandı ( Tablo 1). Katılımcıların medeni durumları branşlara göre istatistiksel olarak anlamlı farklılık göstermedi $(p=0,392)$.

Katılımcıların çalıştıkları kurum branşlara göre istatistiksel olarak anlamlı farklılık gösterdi $(p<0,05)$. Üniversite hastanesinde asistan doktor sayısı daha yüksek, eğitim ve araştırma hastanesindeyse uzman doktor sayısı daha yüksek bulundu. Uzman doktorların $\% 57,9^{\prime} u$, teknikerlerin $\% 44^{\prime}$ ü ve asistan doktorların \%3,7'si 5-10 yıl ameliyathane çalışma süresine sahipti $(p<0,001)$. Uzman doktorların $\% 63,2$ 'si, asistan doktorların \%92'si ve teknikerlerin $\% 51,9^{\prime}$ u 1-5 yıl arası tecrübeye sahipti $(p=0,005)$. 
Tablo 1. Branşlara Göre Cinsiyet Dağılımı

\begin{tabular}{lcccc}
\hline & & \multicolumn{2}{c}{ Cinsiyet } & \multirow{2}{*}{ Toplam } \\
\cline { 2 - 4 } & & Kadın & Erkek & \\
\hline \multirow{2}{*}{ Uzman Doktor } & $\mathrm{n}$ & 11 & 8 & 19 \\
& $\%$ & 57,9 & 42,1 & 100 \\
\hline \multirow{2}{*}{ Asistan Doktor } & $\mathrm{n}$ & 10 & 17 & 27 \\
& $\%$ & 37,0 & 63 & 100 \\
\hline \multirow{2}{*}{ Tekniker* } & $\mathrm{n}$ & 14 & 40 & 54 \\
& $\%$ & 25,9 & 74,1 & 100 \\
\hline \multirow{2}{*}{ Toplam } & $\mathrm{n}$ & 35 & 65 & 100 \\
& $\%$ & 35 & 65 & 100 \\
\hline
\end{tabular}

$\mathrm{P}=\mathbf{0 , 0 4 1}$

${ }^{*}$ Ki-kare testi post-hoc analizinde ikili karşılaştırma sonucu istatistiksel olarak anlamlı farklılık

Asistan doktorların \%77'sinin anestezi doktorluğunu öncelikli tercih ettiği saptanmışken bu oran uzman doktorlarda $\% 42,1$ olarak bulundu (Tablo 2).

Tablo 2. Branşlara Göre Öncelikli Meslek Tercihi Dağılımı

\begin{tabular}{lcccc}
\hline & & \multicolumn{2}{c}{$\begin{array}{c}\text { Anestezi Doktorluğu-Teknikerliği } \\
\text { öncelikli tercihiniz mi? }\end{array}$} & \multirow{2}{*}{ Toplam } \\
\cline { 2 - 4 } & & Evet & Hayır & \\
\hline \multirow{2}{*}{ Uzman Doktor* } & $\mathrm{n}$ & 8 & 11 & 19 \\
& $\%$ & 42,1 & 57,9 & 100 \\
\hline \multirow{2}{*}{ Asistan Doktor } & $\mathrm{n}$ & 21 & 6 & 27 \\
& $\%$ & 77,8 & 22,2 & 100 \\
\hline \multirow{2}{*}{ Tekniker } & $\mathrm{n}$ & 24 & 30 & 54 \\
& $\%$ & 44,4 & 55,6 & 100 \\
\hline \multirow{2}{*}{ Toplam } & $\mathrm{n}$ & 53 & 47 & 100 \\
& $\%$ & 53 & 47 & 100 \\
\hline \multirow{2}{*}{$\mathrm{N}=0,010$} & & & &
\end{tabular}

$\mathrm{P}=\mathbf{0 , 0 1 0}$

${ }^{*}$ Ki-kare testi post-hoc analizinde ikili karşılaştırma sonucu istatistiksel olarak anlamlı farklılık

Uzman doktorların \%63,2'si meslek yaşantılarının mesleki açıdan beklentilerinin karşıladığını belirtirken bu oran asistan doktorlarda $\% 77,8$ ve teknikerlerde $\% 44,4$ olarak bulundu. Asistan doktorlarda teknikerlere kıyasla istatistiksel olarak anlamlı fark saptandı $(p=0,014)$ (Tablo 3). Katılımcıların mesleklerini severek yürütmelerindeki esas belirleyici faktörler incelendiğinde, \%43'ünde ekonomik nedenler, \%34'ündeyse mesleğini sevme faktörünün etkili olduğu saptandı. Branşlar arasında istatistiksel olarak fark saptanmadı.

Tablo 3. Branşlara Göre Mesleki Açıdan Beklentileri Karşılanması

\begin{tabular}{lcccc}
\hline & \multicolumn{3}{c}{$\begin{array}{c}\text { Mesleki açıdan beklentileri karşılama } \\
\text { durumu }\end{array}$} & Toplam \\
\cline { 2 - 4 } & & Evet & Hayır & \\
\hline \multirow{2}{*}{ Uzman Doktor } & $\mathrm{N}$ & 12 & 7 & 19 \\
& $\%$ & 63,2 & 36,8 & 100 \\
\hline \multirow{2}{*}{ Asistan Doktor } & N & 21 & 6 & 27 \\
& $\%$ & 77,8 & 22,2 & 100 \\
\hline \multirow{2}{*}{ Tekniker } & $\mathrm{N}$ & 24 & 30 & 54 \\
\hline \multirow{2}{*}{ Toplam } & $\%$ & 44,4 & 55,6 & 100 \\
\hline \multirow{2}{*}{$\mathrm{P}=\mathbf{0 , 0 1 4}$} & $\mathrm{N}$ & 57 & 43 & 100 \\
& $\%$ & 57 & 43,0 & 100 \\
\hline
\end{tabular}

${ }^{*}$ Ki-kare testi post-hoc analizinde ikili karşılaştırma sonucu istatistiksel olarak anlamlı farklılık
Katılımcıların günlük sıkıntılarının iş yaşantısını olumsuz etkileme durumları branşlara göre nasıl değiştiği incelendiğinde istatistiksel olarak anlamlı fark saptandı $(p=0,002)$. Asistanların \%63'ü, teknikerlerin \%29,6'sı ve uzman doktorların \%26,3'ü bazen özel yaşantısının iş yaşantısını etkilediğini belirtti. Katılımcıların ruh sağlıklarının antidepresan kullanmayı gerektirecek kadar bozuk olduğunu düşünme durumları incelendiğinde, meslek grupları arasında istatistiksel olarak fark saptanmadı. Doktorların \%19,2'si ruh sağlıklarının antidepresan kullanmayı gerektirecek kadar bozuk olduğunu düşündüklerini belirtti (Tablo 4).

Tablo 4. Branşlara Göre Ruh Sağlığının Antidepresan Kullanmayı Gerektirecek Kadar Bozuk Olduğunu Düşünme Durumu

\begin{tabular}{|c|c|c|c|c|}
\hline & & \multicolumn{2}{|c|}{$\begin{array}{c}\text { Ruh sağıı̆ınızın antidepresan kullanmayı } \\
\text { gerektirecek kadar bozuk olduğunu düşü- } \\
\text { nüyor musunuz? }\end{array}$} & \multirow[t]{2}{*}{ Toplam } \\
\hline & & Evet & Hayır & \\
\hline \multirow{2}{*}{ Uzman Doktor } & $\mathrm{N}$ & 4 & 15 & 19 \\
\hline & $\%$ & 21,1 & 78,9 & 100 \\
\hline \multirow{2}{*}{ Asistan Doktor } & $\mathrm{N}$ & 3 & 24 & 27 \\
\hline & $\%$ & 11,1 & 88,9 & 100 \\
\hline \multirow{2}{*}{ Tekniker } & $\mathrm{N}$ & 12 & 41 & 53 \\
\hline & $\%$ & 22,6 & 77,4 & 100 \\
\hline \multirow{2}{*}{ Toplam } & $\mathrm{N}$ & 19 & 80 & 99 \\
\hline & $\%$ & 19,2 & 80,8 & 100 \\
\hline $\mathrm{P}=0,453$ & & & & \\
\hline
\end{tabular}

Katılımcıların bağımlııı yapıcı madde kullanım durumları incelendiğinde uzman doktorların 26,3'ü alkol, asistan doktorların \%29,6'sı sigara ve teknikerlerin \%42,6'sının sigara kullandığı saptandı $(p=0,014)$ (Tablo 5). Katılımcıların meslek yaşamlarında olumsuz hasta davranışı ile karşılaşma durumları değerlendirildiğinde uzman doktorların $\% 15,8^{\prime}$ inin sıklıkla, asistan doktorların \%59,3'ünün bazen ve tekniklerin \%46,3'ünün nadiren olumsuz hasta davranışları ile karşılaştığı görüldü.

Tablo 5. Branşlara Göre Kullanılan ve Bağımlılık Yapan Maddelerin Dağılım

\begin{tabular}{|c|c|c|c|c|c|}
\hline & & \multicolumn{3}{|c|}{$\begin{array}{l}\text { Kullandığınız bağımlılık yapan mad- } \\
\text { deler }\end{array}$} & \multirow[t]{2}{*}{ Toplam } \\
\hline & & Sigara & Alkol & Hiçbiri & \\
\hline \multirow{2}{*}{ Uzman Doktor ${ }^{*}$} & $\mathrm{~N}$ & 1 & 5 & 13 & 19 \\
\hline & $\%$ & 5,3 & 26,3 & 68,4 & 100 \\
\hline \multirow{2}{*}{ Asistan Doktor } & $\mathrm{N}$ & 8 & 5 & 14 & 27 \\
\hline & $\%$ & 29,6 & 18,5 & 51,9 & 100 \\
\hline \multirow{2}{*}{ Tekniker* } & $\mathrm{N}$ & 23 & 3 & 28 & 54 \\
\hline & $\%$ & 42,6 & 5,6 & 51,9 & 100 \\
\hline \multirow{2}{*}{ Toplam } & $\mathrm{N}$ & 32 & 13 & 55 & 100 \\
\hline & $\%$ & 32 & 13 & 55 & 100 \\
\hline \multicolumn{6}{|l|}{$\mathrm{P}=0,014$} \\
\hline
\end{tabular}

Uzman doktorların \%68,4'ünün, asistan doktorların $\% 96,3$ 'ünün ve teknikerlerin $\% 66,7$ 'sinin yeterli süre ve nitelikte uyduğunu düşünmediği saptandı $(p=0,011)$ (Tablo $6)$. 
Tablo 6. Branşlara Göre Yeterli Süre ve Nitelikte Dinlenme Durumu

\begin{tabular}{lcccc}
\hline & & \multicolumn{2}{c}{$\begin{array}{c}\text { Yeterli süre ve nitelikte uyudu- } \\
\text { ğunuzu düşünüyor musunuz? }\end{array}$} & Toplam \\
\cline { 2 - 4 } & $\mathrm{N}$ & 6 & Hayır & \\
\hline \multirow{2}{*}{ Uzman Doktor } & $\%$ & 31,6 & 13 & 19 \\
& $\mathrm{~N}$ & 1 & 68,4 & 100 \\
\hline \multirow{2}{*}{ Asistan Doktor* } & $\%$ & 3,7 & 26 & 27 \\
& $\mathrm{~N}$ & 18 & 96,3 & 100 \\
\hline \multirow{2}{*}{ Tekniker } & $\%$ & 33,3 & 36 & 54 \\
\hline \multirow{2}{*}{ Toplam } & $\mathrm{N}$ & 25 & 75 & 100 \\
\hline P=0,011 & $\%$ & 25 & 75 & 100 \\
\hline${ }^{*}$ Ki-kare testi post-hoc analizinde ikili karşılaştırma sonucu istatistiksel \\
olarak anlamlı farklılık
\end{tabular}

Katılımcıların mesleklerinin kendilerini maddi anlamda tatmin etme durumu incelendiğinde branşa göre istatistiksel olarak anlamlı fark saptanmadı. Uzman doktorların $\% 36,8^{\prime} i$, asistan doktorların $\% 44,4^{\prime} \ddot{u}$ ve teknikerlerin $\% 68,5^{\prime} i$ emekli olmadan işlerinden ayrılmayı düşündüğü saptandı $(p<0,05)$. Uzman doktorların $\% 47,4$ 'ünün, asistan doktorların \%11,1'inin ve teknikerlerin \%35,2'sinin iş yaşamındaki sorunlar nedeniyle işe gitmediği saptandı $(p<0,05)$.

Uzman doktorların \%52,6'sı, asistan doktorların \%51,9'u ve teknikerlerin $\% 25,9^{\prime}$ u geçmişe geri dönecek olsalar tekrar bu mesleklerini tercih etmeyeceklerini belirtti $(p=0,026)$ (Tablo 7).

Tablo 7. Branşlara Göre Geçmişe Dönmek Mümkün Olsa Mesleğini Tekrar Seçme Durumu

\begin{tabular}{|c|c|c|c|c|}
\hline & \multicolumn{3}{|c|}{$\begin{array}{c}\text { Geçmişe dönmek mümkün olsa mes- } \\
\text { leğinizi yine seçer miydiniz? }\end{array}$} & \multirow[t]{2}{*}{ Toplam } \\
\hline & & Evet & Hayır & \\
\hline \multirow{2}{*}{ Uzman Doktor } & $\mathrm{N}$ & 10 & 9 & 19 \\
\hline & $\%$ & 52,6 & 47,4 & 100 \\
\hline \multirow{2}{*}{ Asistan Doktor } & $\mathrm{N}$ & 14 & 13 & 27 \\
\hline & $\%$ & 51,9 & 48,1 & 100 \\
\hline \multirow{2}{*}{ Tekniker* } & $\mathrm{N}$ & 14 & 40 & 54 \\
\hline & $\%$ & 25,9 & 74,1 & 100 \\
\hline \multirow{2}{*}{ Toplam } & $\mathrm{N}$ & 38 & 62 & 100 \\
\hline & $\%$ & 38 & 62 & 100 \\
\hline
\end{tabular}

$\mathbf{P}=\mathbf{0 , 0 2 6}$

${ }^{*}$ Ki-kare testi post-hoc analizinde ikili karşılaştırma sonucu istatistiksel olarak anlamlı farklılı

Katılımcıların iş yaşamında kendisini duygusal ve düşünsel olarak tükenmiş hissetme durumları incelendiğinde sonucun branşa göre farklılaşmadığı saptandı. Araştırmaya katılan doktorların \%48'inin bazen iş yaşamında kendini duygusal olarak, \%46'sının ise düşünsel olarak tükenmiş hissettiği saptandı. Uzman doktorların \%47,4'ünün, asistan doktorların \%63'ünün ve teknikerlerin \%24,1'inin bazen işini yaparken hastalara karşı duyarsızlaştığı saptandı ( $p=0,002$ ) (Tablo 8). Uzman doktorların \%68,4'ü, asistan doktorların \%55,6'sı ve teknikerlerin \%24,1'i mesleklerinin kendilerini duygusal olarak tatmin ettiğini belirtti $(p<0,05)$.
Tablo 8. Branşlara Göre İş Yaparken Hastalara Karşı Duyarsızlaşma Hissinin Dağılım

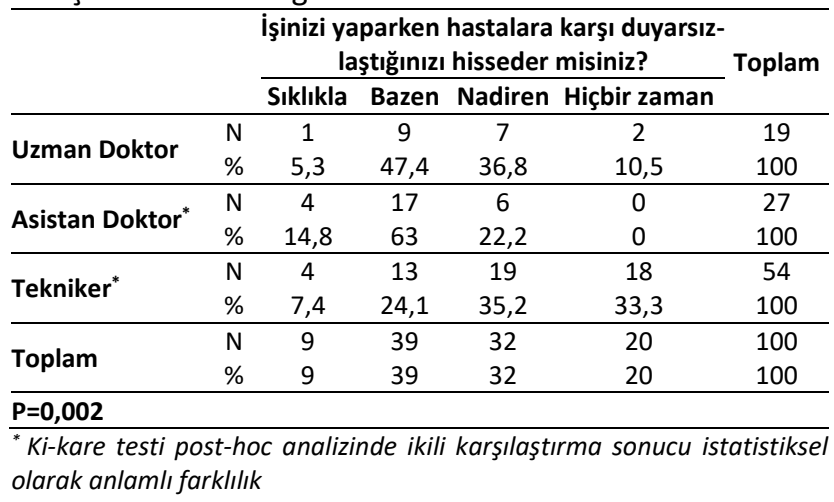

Doktorlarda içsel doyum puan ortalaması 3,10; dışsal doyum için 2,57; genel doyum puanı 2,89 bulundu. Maslach tükenmişlik ölçeği alt boyut puanları duygusal tükenme için 2,24, duyarsızlaşma için 1,20 ve kişisel başarı için 2,58 olarak hesaplandı (Tablo 9).

Tablo 9. Ölçek Puanlarının Tanımsal Değerleri

\begin{tabular}{lcccc}
\hline & N & Min & Mak & Ort $\pm S . S$ \\
\hline Içsel Doyum & 100 & 1,17 & 4,25 & $3,10 \pm 0,70$ \\
Dışsal Doyum & 100 & 1,00 & 4,25 & $2,57 \pm 0,84$ \\
Genel Doyum Puanı & 100 & 1,15 & 4,05 & $2,89 \pm 0,71$ \\
Duygusal Tükenme & 100 & 0,67 & 4,00 & $2,24 \pm 0,76$ \\
Duyarsızlaşma & 100 & 0,00 & 4,00 & $1,20 \pm 0,86$ \\
Kişisel Başarı & 100 & 0,88 & 3,88 & $2,58 \pm 0,68$ \\
\hline
\end{tabular}

İçsel doyum ölçeği alt boyut puanıyla dışsal doyum, genel doyum ve kişisel başarı puanı arasında pozitif yönlü ve istatistiksel olarak anlamlı bir ilişki bulundu. İçsel doyum puanıyla kişisel başarı arasındaki ilişkinin zayıf olduğu saptanırken, dışsal ve genel doyum puanı ilişkisinin oldukça güçlü olduğu görüldü. Diğer yandan içsel doyum puanıyla duygusal tükenme ve duyarsızlaşma arasında negatif yönlü ve zayıf bir ilişki saptandı.

Dışsal doyum puanı incelendiğinde duygusal tükenme ve duyarsızlaşma arasında negatif yönlü ve zayıf bir ilişki saptandı. Kişisel başarıyla dışsal doyum arasında istatistiksel olarak anlamlı bir ilişki saptanmazken, genel doyum puanıyla duygusal tükenme, duyarsızlaşma ve kişisel başarı arasında istatistiksel olarak anlamlı bir ilişki saptandı. Genel doyum puanının duygusal tükenme ve duyarsızlaşmayla negatif yönlü, kişisel başarıyla pozitif yönlü bir ilişkisinin olduğu görüldü (Tablo 10).

Mineseto doyum ölçeği alt boyut puanlarında içsel doyum, dışsal doyum ve genel doyum puanı branşlara göre istatistiksel olarak anlamlı farklılık gösterdi. Duygusal tükenme ve duyarsızlaşma ile negatif yönlü bir ilişkisi olduğunu saptadığımız doyum ölçeği alt puanlarının uzman doktorlarda en yüksek, teknikerlerdeyse en düşük olduğunu saptadık. 
Tablo 10. Ölçekler Arasında Iliş̧ki

\begin{tabular}{|c|c|c|c|c|c|c|c|}
\hline & & İçsel Doyum & Dışsal Doyum & Genel Doyum Puanı & Duygusal Tükenme & Duyarsızlaşma & Kişisel Başarı \\
\hline & $r$ & 1 & $0,787^{* *}$ & $0,957^{* *}$ & $-0,394^{* *}$ & $-0,285^{* *}$ & $0,243^{*}$ \\
\hline \multirow[t]{3}{*}{ İçsel Doyum } & $\mathrm{p}$ & & 0,000 & 0,000 & 0,000 & 0,004 & 0,015 \\
\hline & $\mathrm{N}$ & 100 & 100 & 100 & 100 & 100 & 100 \\
\hline & $r$ & $0,787^{* *}$ & 1 & $0,932^{* *}$ & $-0,433^{* *}$ & $-0,248^{*}$ & 0,127 \\
\hline \multirow[t]{3}{*}{ Dışsal Doyum } & $\mathrm{p}$ & 0,000 & & 0,000 & 0,000 & 0,013 & 0,209 \\
\hline & $\mathrm{N}$ & 100 & 100 & 100 & 100 & 100 & 100 \\
\hline & $r$ & $0,957^{* *}$ & $0,932^{* *}$ & 1 & $-0,435^{* *}$ & $-0,284^{* *}$ & $0,202^{*}$ \\
\hline \multirow[t]{3}{*}{ Genel Doyum Puanı } & $p$ & 0,000 & 0,000 & & 0,000 & 0,004 & 0,044 \\
\hline & $\mathrm{N}$ & 100 & 100 & 100 & 100 & 100 & 100 \\
\hline & $r$ & $-0,394^{* *}$ & $-0,433^{* *}$ & $-0,435^{* *}$ & 1 & $0,539^{* *}$ & $-0,040$ \\
\hline \multirow[t]{3}{*}{ Duygusal Tükenme } & $\mathrm{p}$ & 0,000 & 0,000 & 0,000 & & 0,000 & 0,696 \\
\hline & $\mathrm{N}$ & 100 & 100 & 100 & 100 & 100 & 100 \\
\hline & $r$ & $-0,285^{* *}$ & $-0,248^{*}$ & $-0,284^{* *}$ & $0,539^{* *}$ & 1 & $-0,174$ \\
\hline \multirow[t]{3}{*}{ Duyarsızlaşma } & $p$ & 0,004 & 0,013 & 0,004 & 0,000 & & 0,083 \\
\hline & $\mathrm{N}$ & 100 & 100 & 100 & 100 & 100 & 100 \\
\hline & $r$ & $0,243^{*}$ & 0,127 & $0,202^{*}$ & $-0,040$ & $-0,174$ & 1 \\
\hline \multirow[t]{2}{*}{ Kişisel Başarı } & $p$ & 0,015 & 0,209 & 0,044 & 0,696 & 0,083 & \\
\hline & $\mathrm{N}$ & 100 & 100 & 100 & 100 & 100 & 100 \\
\hline
\end{tabular}

**. Correlation is significant at the 0.01 level (2-tailed)

*. Correlation is significant at the 0.05 level (2-tailed).

Maslach tükenmişlik ölçeği alt boyut puanları branşlara göre istatistiksel olarak anlamlı farklılık göstermedi.

Üç branş içinde cinsiyete göre Minesota doyum ölçeği ve Maslach tükenmişlik ölçeği alt boyutlarının nasıl değiştiği araştırıldığında, uzman doktor ve teknikerlerde cinsiyete göre anlamlı farklılık saptanmadı. Ancak asistan doktorlarda duygusal tükenme ve duyarsızlaşma puanları cinsiyete göre istatistiksel olarak anlamlı farklılık gösterdi $(p<0,05)$. Erkek asistan doktorlarda duygusal tükenme ve duyarsızlaşma puanlarının daha yüksek olduğu görüldü.

Üç branş içinde medeni duruma göre Minesota doyum ölçeği ve Maslach tükenmişlik ölçeği alt boyutlarının nasıl değiştiği araştırıldı. Uzman ve asistan doktorlarda tükenmişlik ölçeği alt boyut puanları medeni durumlarına göre anlamlı farklılık göstermezken, teknikerde duyarsızlaşma puanı medeni durumuna göre istatistiksel olarak anlamlı farklılık gösterdi $(p<0,05)$. Bekâr teknikerlerin duyarsızlaşma puanının daha yüksek olduğu saptandı.

\section{Tartışma}

Mesleki tükenmişliğin bireysel değişkenlerden çok, meslek ve iş ortamı ile ilgili değişkenlerden etkilenen örgütsel bir sorun olduğu görüşünün yaygın olduğu görülmektedir. Maslach ve Leiter (1997)'in oluşturduğu tükenmişlik modelinde öncekilerden farklı olarak bireysel ve örgütsel faktörler bir arada ele alınmış ve çalışma hayatı alanları oluşturulmuştur (9).

Literatürü incelediğimizde bazı çalışmalarda kadın hekimlerde, bazı çalışmalardaysa erkek hekimlerde tükenmişliğin daha sık olduğu görüldü (3-15). Araştırma sonuçlarımız cinsiyet farkının tükenmişlik üzerinde etkili olmadığını gösterdi ve bu sonuç literatürdeki bazı çalışma sonuçlarıyla örtüşmektedir (16). Bu sonuç, kadın ve erkeklerin kişilik yapıları, çalışma ortamı ve özel hayattaki rolleriyle açıklanabilir. Ayrıca kurum içerisindeki faktörlerin kadın ve erkek çalışanları eşit ölçüde etkilediğinin bir göstergesi olabilir.
Bu sonuç son yıllarda değişen dünya sağlık politikalarının hekimlere yansımasının bir etkisi olarak yorumlanabileceği gibi, gelişmekte olan ülkelerin sağlık dönüşüm programlarının, cinsiyet farkı gözetmeksizin tüm hekimlerin tükenmişliği üzerine olan etkisiyle de açıklanabilir.

Literatürdeki çalışmalar incelendiğinde medeni durumun tükenmişlik düzeyine etkisiyle ilgili sonuçlar farklılık göstermektedir. Ergin ve ark. evlenmemiş sağlık çalışanlarının daha fazla duyarsızlaşma yaşadıklarını, Taycan ve ark. evli sağlık çalışanlarının kişisel başarı düzeylerinin daha yüksek olduğunu, Doğan ve ark. ise boşanmış, dul veya ayrı yaşayan sağlık çalışanlarında duygusal tükenmenin daha yüksek olduğunu bulmuşlardır (3-17). Çalışma sonuçlarımız birçok literatür çalışmasıyla uyumlu olarak bekâr anestezi uygulayıcılarındaki duygusal tükenmişlik ve duyarsızlaşmanın evlilere kıyasla daha yüksek, kişisel başarının ise daha düşük olduğunu gösterdi. Bu durum evlilerde, ikili ilişkiler ve krizle başa çıkma deneyimlerinin fazla olmasına bu sayede sorun çözme becerilerinin daha gelişmiş olmasına bağlanabilir $(2,18)$. Diğer bir önemli faktör ise aile ortamının, bireyin iş stresiyle başa çıkabilmesi için sosyal destek sağlıyor olması olabilir (19). Buradan yola çıkarak sosyal destek sistemlerinin varlığıyla, tükenmişliğin azaltabileceği sonucu öngörülebilir.

Aslan ve ark. tarafından yapılan bir çalışmada hekimlerin meslekte çalışma yılı ile tükenme durumları arasındaki ilişki incelenmiş ve çalışma süresi 5-9 yıl olan hekimlerde duyarsızlaşmanın diğer gruplardan daha yüksek olduğu ve en yüksek duygusal tükenmenin 10-14 yıldır çalışan hekimlerde görüldüğü saptanmıştır (6). Diğer bir çalışmada meslekte çalışma süresi en az olan grup (0-5 yıl) kişisel başarı açısından en düşük puanı almıştır (20). Çalışma sonuçlarımız incelendiğinde 0-5 yıl çalışma süresi olan grupta hem duygusal tükenme hem de duyarsızlaşma değerlerinin anlamlı olarak yüksek olduğu ve kişisel başarının etkilenmediği saptanmıştır. Bu durumun 5 yılın altında çalışma süresine sahip hekimlerin ağırlıklı olarak asistanlık döneminde 
olmaları, deneyim ve bilgi birikiminin nispeten daha az olması ve asistanlık döneminde görülen çalışma şartları ile ilişkilendirilebilineceği kanaatindeyiz.

Soler ve Shanafelt'in çalışma sonuçlarına benzer şekilde biz de ileri yaş olan, yüksek akademik ünvana sahip ve meslekte daha uzun süre geçiren hekimlerde tükenmenin daha az olduğunu bulduk $(8,21,22)$. Amoafo'nun çalışmasıyla uyumlu olarak, aynı kurumda daha uzun süre çalışanlarda, tükenmişliğin daha az olduğunu gözledik (23). Bu sonuçlar, mesleki tecrübenin artmasının yanı sıra çalışılan kuruma dair tecrübenin artmasının da tükenmişliği azaltabileceğini destekler niteliktedir.

Hekimlerde, işyerinde tükenmeye yol açan en önemli stres etkeni olarak çalışma koşulları gösterilmektedir $(24,25)$. Birçok sağlık kuruluşunda asistanlığın ilk yıllarında izin kullanma imkânının çoğunlukla olmaması veya yetersiz oluşu nedeniyle tükenme sıklığı artmaktadır. Ayrıca literatürde nöbet sayısı fazla, günlük çalışma saatleri uzun ve günlük uyku süresi daha kısa olan hekimlerde duygusal tükenme ve depersonalizasyon oranlarının daha yüksek olduğu saptanmıştır $(24,25)$. Bu durum asistan hekimlerdeki artmış tükenmişliğin bir başka nedeni olabilir. Tükenme Sendromu, iş koşulları ve çevresel koşullar ile ilişkilidir. Sağlık meslek alt gruplarına göre işyeri memnuniyeti ve çalışma şartları incelendiğinde doktorların ve teknikerlerin yarısından fazlasının işyerinden memnun olmadıkları ve nöbet sonrası izin kullanmadıkları saptandı. İşyeri memnuniyetinin, nöbet sonrası izin kullanmamanın, hekimlerin hastaları ya da meslektaşları tarafından takdir edilmediği düşüncelerinin tükenmişlikle ilişkili olduğu düşüncesindeyiz. Ayrıca doktorların ve teknikerlerin yüksek oranda hastane dışı etkinliklere zaman ayıramadıklarını belirtmiş olmaları da diğer bir tükenmişlik nedeni olabilir.

Genel popülâsyonla kıyaslandığında psikoaktif madde kullanımı hekimlerde daha sık gözlenmektedir. Anestezi hekimleri için hem bu maddelere kolay ulaşabilir olmaları hem de olumsuz iş koşullarının etkisiyle bu risk daha da artmıştır $(26,27)$. Anestezistlerin en sık kullandığı ajan alkoldür (\%50), bunu opioidler (\%33), stimülanlar (\%8) ve diğerleri takip etmektedir (28). Hekimler intihar riski açısından değerlendirildiğinde genel popülâsyona ve diğer akademisyenlere göre daha yüksek risk altındadırlar $(29,30)$.

Çoğu durumda çalışma alanındaki yüksek riskli bireyin belirlenmesi zor olmaktadır. Ancak madde kullanımı ya da intihar riski olan anestezi çalışanlarının belirlenip uygun psikiyatrik tedavinin erken dönemde başlanılması intihar riskinin azaltılması için önemlidir.

Çalışma sonuçlarımız incelendiğinde katılımcılara yöneltilen intihar ve madde bağımlılığı ile ilişkili soruların yanıtları bu meslek grubunun yüksek risk altında olduğuna işaret etmektedir. Katılımcıların yaklaşık beşte biri “Ruh sağlığınızın antidepresan kullanmayı gerektirecek kadar bozuk olduğunu düşünüyor musunuz?" sorusuna "Evet" yanıtını verdi. Madde bağımlılığı ve intiharın çoğunlukla başka psikiyatrik ko-morbiditelerle birlikte görüldüğü düşünülürse bu oran oldukça yüksektir. Katılımcıların \%19,2'sinin kendisini tükenmiş hissettiğini belirtmesi de aslında psikiyatrik bozukluk oranının tahmin edilenden daha yüksek olabileceğine işaret etmektedir. Tüm bunlar bir arada düşünüldüğünde bu meslek grubunun özellikle çalışma koşulları nedeniyle madde bağımlılığı ve intihar riski altında olduğunu söyleyebiliriz. Çalışmamızda \%13 oranında alkol bağımlılığı mevcuttu. Çalışmamızda tükenmişlik sendromu kötü uyku paterni, kişiler arası çatışmalar, depresyon, madde bağımlılığı ve nöbet sonrası kazalar gibi olumsuz durumlarla ilişkili bulunmuş, ayrıca literatürle uyumlu olarak tükenmişlik sendromu olanlarda daha fazla mesleği bırakma eğilimi gözlenmiştir (31). Araştırmaya katılanlardan tekrar meslek seçseydiniz sağlık sektörünü kaçıncı sırada seçerdiniz sorusuna 38 kişi (\%38) bu mesleği tekrar asla seçmeyeceklerini ifade etmiş olmaları sağlık çalışanlarının yaşamı için çok önemli olan iş hayatında aslında ne kadar isteksiz olduklarını yansıtmaktadır.

"Çalışanların fiziksel ve duygusal açıdan kendilerini aşırı yorgun ve yıpranmış hissetmeleri" anlamına gelen duygusal tükenme şiddeti arttıkça duygusal bağlılık azalmaktadır. Bir diğer tükenmişlik boyutu olan ve "çalışanların yaşadıkları duygusal tükenmeye karşı bir tepki olarak, diğer kişilerle aralarına mesafe koyma eylemi" anlamına gelen duyarsızlaşma da tüm bağlılık boyutları ile negatif ilişkilidir. Tükenmişlik boyutlarının duygusal bağııık üzerindeki azaltıcı etkileri sırasıyla "duygusal tükenmişlik, duyarsızlaşma ve düşük kişisel başarı hissi" şeklindedir. Tükenmişlik boyutlarının devam bağlılığı üzerindeki azaltıcı etkileri de sırasıyla "düşük kişisel başarı hissi, duygusal tükenmişlik ve duyarsızlaşma" şeklinde ortaya çıkmıştır. Tükenmişlik boyutlarının normatif bağııık üzerindeki azaltıcı etkileri sırasıyla "duygusal tükenmişlik, duyarsızlaşma ve düşük kişisel başarı hissi" şeklinde gerçekleşmiştir.

Çalışmamızın bazı limitasyonları vardır. Çalışmamız sadece iki merkezde sınırlı sayıda çalışan üzerinde gerçekleştirildiğinden sonuçlar genellenemez. Yoğun bakımda çalışma faktörünün tükenmişlikle ilişkisi değerlendirilmedi.

Sonuç olarak, "Çalışanların günlük iş yükünün fazlalığı tükenmişlik düzeylerini arttırır." Bu varsayım tutarlıdır. Çünkü kapasitelerinin çok üstünde iş istenip bunu kısa bir süre içinde bitirme zorunluluğu, çalışanın çok çalışıp yorulmasına, stresli, gergin olmasına ve sonuçta tükenmişliğe yol açmaktadır.

"Çalışanların çalışma ortamından memnun olma seviyesi tükenmişlik düzeylerini etkilemektedir." Bu varsayım tutarlıdır. Çünkü çalışma ortamının kargaşa halinde olması, işleyişteki problemler, ekip ruhunun yeterince oluşmaması gibi faktörler personeli işten soğutup verilen hizmetin kalitesini etkilemektedir. Bu faktörler düzeltilirse personelin memnuniyeti artacaktır. Bu da onu motive edip tükenmişlikle karşı karşıya getirmekten alıkoyacaktır.

"Çalışanların üstlerinden takdir görme durumu tükenmişlik seviyesini etkilemektedir." Bu varsayım tutarlıdır. Çünkü çalışanların yaptığı işin, emeğin karşılığında takdir edilmesi 
kişinin işe bağlılığında ve motivasyonunun artışında etkilidir. Ancak bu konuda yetersiz kalındığında çalışanın şevki kırılıp moralinde düşüş yaşanır. Bu durum uzun sürede çaIışanı tükenmişliğe itebilir.

"Çalışılan birimdeki personel eksikliği tükenmişlik düzeyine etki etmektedir." Bu varsayım tutarlıdır. Çünkü personelin eksik olması çalışanların yoğun iş temposu ve kapasitesinin üstünde performans göstermesine neden olur. Sonuçta çalışan yorgun, bitkin ve gergin bir hal alır. Bu da çalışanı tükenmişliğe itebilir.

"İ̧̧ ortamından kaynaklanan stres "tükenmişlik düzeylerini arttırır." Bu varsayım tutarlıdır. Çünkü iş ortamında stres yaşanması sonucunda bireyin iş yapma düzeyi ve işten aldığı doyumda azalma gözlenir. Çalışanın kendini iş yüzünden çok hırpalamasıyla fiziksel ve psikolojik sağlık durumunda bozulmalar meydana gelir ve stresin kronikleşmesi bireyde tükenmişlik yaşanmasına neden olabilir.

Sağlık çalışanlarında tükenmişlik sendromu risk faktörlerinin belirlenmesi ve bu risk faktörlerinden yola çıkarak tükenmişlik sendromu gelişiminin önlenmesine yönelik çalışmalar ciddi ölçüde faydalı olabilir. Bu konuda özellikle karşılaştırmalı çalışmalar yapılarak daha kesin değerlendirme olanağı sağlanabilir.

Etik onam: Çalışma için 07.10.2016 tarih ve 319 sayılı etik kurul kararı ile Dicle Üniversitesi Tıp Fakültesi Etik Kurulu'ndan onay alındı.

\section{Yazar Katkıları:}

Konsept: M.B, F.Ç

Literatür Tarama: M.B, F.Ç

Tasarım: M.B, F.Ç

Veri toplama: M.B, F.C

Analiz ve yorum: M.B, F.C

Makale yazımı: M.B, F.Ç

Eleştirel incelenmesi: M.B, F.Ç

Fon sağlama (mevcut ise): M.B, F.Ç

Çıkar Çatışması: Yazarlar, araştırmada rapor edilen sonuçlar ve/veya tartışmalarla ilgili olarak herhangi bir çıkar çatışması veya başka bir rekabet çıkarı olmadığını beyan etmişlerdir.

Finansal Destek: Araştırma kapsamında herhangi bir kurum ya da kuruluştan finansal destek sağlanmamıştır.

\section{Kaynaklar}

1. Freudenberger HJ. "Staff Burnout". Journal of Social Issues. 1974; 30: 159-65.

2. Maslach C, Jackson SE. "The Measurement of Experienced Burnout". Journal of Occupational Behavior. 1981; 2: 99-113.

3. Ergin C. Doktor ve Hemşirelerde Tükenmişlik ve Maslach Tükenmişlik Ölçeğinin Uyarlanması. VII. Ulusal Psikoloji Kongresi Bilimsel Çalışmaları. Türk Psikologlar Derneği Yayını. Hacettepe Üniversitesi, Ankara 1993.

4. Çakir Ö, Tanğ Y. Türkiye'de sağlık çalışanlarında tükenmişlik sendromu: bir meta analiz çalışması. Is, Guc: The Journal of Industrial Relations \& Human Resources. 2018; 20(4).

5. Sivrikaya S.K, Erişen M. Sağlık çalışanlarının tükenmişlik ve işe bağlı gerginlik düzeylerinin incelenmesi. Anadolu
Hemşirelik ve Sağlık Bilimleri Dergisi. 2019; 22(2): 121-9.

6. Aslan D, Kiper N, Karaağaoğlu E, Topal F, Güdük M, Cengiz ÖS. Türkiye'de Tabip Odalarına Kayıtlı Olan Bir Grup Hekimde Tükenmişlik Sendromu ve Etkileyen Faktörler. Türkiye Tabip Odaları Birliği Yayınları. Ankara, 2005.

7. Selamu M, Thornicroft G, Fekadu A, Hanlon C. Conceptualisation of job-related wellbeing, stress and burnout among healthcare workers in rural Ethiopia: a qualitative study. BMC health services research. 2017; 17(1): 1-11.

8. Mete B, Değer M.S, Pehlivan E. Doktorlarda Mesleki Tükenmişlik Sendromuna Çalışma Yaşam Kalitesinin Etkisi. Anadolu Kliniği Tıp Bilimleri Dergisi. 2020; 25(2): 94-101.

9. Maslach C, Leiter PM. The Truth about Burnout.JosseyBass, San Francisco, Ca. 1997.

10. Shanafelt TD, Sinsky C, Dyrbye LN, Trockel M, West CP. Burnout among physicians compared with individuals with a professional or doctoral degree in a field outside of medicine. In Mayo Clinic Proceedings. 2019; 94(3): 549-51.

11. Dyrbye LN, Shanafelt TD, Balch CM, Satele D, Sloan J, Freischlag J. Relationship between work-home conflicts and burnout among American surgeons: a comparison by sex. Arch Surg. 2011; 146: 211-7

12. Shanafelt TD, Oreskovich MR, Dyrbye LN, Satele DV, Hanks JB, Sloan JA et al. Avoiding burnout: the personal health habits and wellness practices of US surgeons. Ann Surg. 2012; 255: 625-33

13. Giménez Lozano JM, Martínez Ramón JP, Morales Rodríguez FM. Doctors and nurses: a systematic review of the risk and protective factors in workplace violence and burnout. International journal of environmental research and public health. 2021; 18(6): 3280.

14. Amoafo E, Hanbali N, Patel A, Singh P. What are the significant factors associated with burnout in doctors? Occup Med. 2015; 65: 117-21.

15. LaFaver K, Miyasaki JM, Keran CM, Rheaume C, Gulya L, Levin $\mathrm{KH}$, et al. Age and sex differences in burnout, career satisfaction, and well-being in US neurologists. Neurology. 2018; 91(20): e1928-41.

16. Ye J, Wang $H$, Wu H, Ye L, Li $Q$, Ma XY, et al. Burnout among obstetricians and paediatricians: a cross-sectional study from China. BMJ open. 2019; 9(1): e024205.

17. Taycan O, Kutlu L, Çimen S, Aydın N. "Bir Üniversite Hastanesinde Çalışan Hemşirelerde Depresyon ve Tükenmişlik Düzeyinin Sosyodemografik Özelliklerle ilişskisi”. Anatolian Journal Of Psychiatry. 2006; 7: 100-8.

18. Zheng $Q$, Ping $P$, Yang $K$, Zhao RJ, Wang $X$, Ou ZH, et al. Burnout Among Doctors in China Through 2018: A Systematic Review and Meta-Analysis. 2019; Available at SSRN 3487764.

19. Belloch GSL, Renovell FV, Calabuig AJR, Gomez Salinas L. The professional burnout syndrome in resident physicians in hospital medical specialties. Anales de Medicina İnterna. 2000; 17(3): 118-22.

20. Naldan ME, Karayağmurlu A, Yayık M, Arı MA. Ameliyathanede Çalışan Sağlık Profesyonellerinde Tükenmişlik, İş Doyumu Ve Depresyon. Selçuk Tıp Dergisi. 2019; 35(3): 152-8.

21. Soler JK, Yaman H, Esteva M, Dobss F, Asenova RS, Katic $M$, et al; European General Practice Research Network Burnout Study Group. Fam Pract. 2008; 25: 245-65

22. Shanafelt TD, Oreskovich MR, Dyrbye LN, Satele DV, 
Hanks JB, Sloan JA, et al. Avoiding burnout: the personal health habits and wellness practices of US surgeons. Ann Surg. 2012; 255: 625-33.

23. Amoafo $E$, Hanbali N, Patel A, Singh P. What are the significant factors associated with burnout in doctors? Occup Med. 2015; 65: 117-21.

24. Akkaya A, Karadağ M. Ameliyathane Hemşirelerinin ÇaIışma Ortamından Kaynaklanan Mesleki Risklerinin ve Sağlık Sorunlarının Belirlenmesi. Ege Üniversitesi Hemşirelik Fakültesi Dergisi. 2021; 37(1): 11-22.

25. Özsoylu S, Akyıldız B, Dursun A. Bir Üniversite Hastanesinde Çalışan Hemşirelerin Tükenmişlik Düzeyi ve Etkileyen Faktörler. J Pediatr Emerg Intensive Care Med. 2017; 4: 104-9.

26. Yıldız A, Çiçek I, Şanlı ME. Sağlık Çalışanlarında Tükenmişliğin Belirleyicileri: sigara ve Alkol Kullanımına Etkisinin İncelenmesi. Celal Bayar Üniversitesi Sağlık Bilimleri Enstitüsü Dergisi. 2018; 5(3): 126-32.

27. Alves HN, Surjan JC, Nogueira-Martins LA, Marques AC, Laranjeira RR. Clinical and demographical aspects of alcohol and drug dependent physicians. Rev Assoc Med Bras. 2005; 51: 139-43.

28. Jungerman FS, Palhares-Alves HN, Carmona MJ, Conti NB, Malbergier A. Anesthetic drug abuse by anesthesiologists. Rev Bras Anestesiol. 2012; 62: 375-86

29. Schernhammer ES, Colditz GA. Suicide rates among physicians: a quantitative and gender assessment (metaanalysis). Am J Psychiatry. 2004; 161: 2295-302

30. Sheikhmoonesi F, Zarghami M. Prevention of physicians' suicide. Iran J Psychiatry Behav Sci. 2014; 8: 1-3.

31. Malaquin S, Mahjoub Y, Musi A, Zogheib E, Salomon A, Guilbart $M$, et al. Burnout syndrome in critical care team members: A monocentric cross sectional survey. Anaesthesia Critical Care \& Pain Medicine. 2017; 36(4): 223-8. 